\title{
Environmental Education In Higher Education: Reflective Dialogues About The Environment
}

\author{
Larissa Benevides da Costa ${ }^{1}$; Lourivaldo Silva Santos ${ }^{2}$
}

12 Universidade Federal do Pará (UFPA). Avenida Augusto Correa No. 01. Campus Guamá. Belém-Pará-Brasil.

Email: barros_lara@hotmail.com, 1sslouri@gmail.com

Received: February $11^{\text {th }}, 2017$

Accepted: March $17^{\text {th }}, 2017$

Published: June $30^{\text {th }}, 2017$

Copyright $(2016$ by authors and Institute of Technology Galileo of Amazon (ITEGAM). This work is licensed under the Creative Commons Attribution International License (CC BY 4.0).

http://creativecommons.org/lic enses/by/4.0/ (c) (1)(3) Open Acces:

\begin{abstract}
The article presents a reflection on the possibility of dialoguing about the Environment in the scope of Higher Education. Thus, in order to extend the integral understanding of its dimensions (biological, political, social and economic), it seeks to break with its restricted relation in preserving living beings and nature, starting to construct new forms of articulation of this with teacher education. On this, we opted for action research, whose methodology made use of the qualitative approach, with data collected through documentary and bibliographic observation and research. The main objective was to analyze which theoretical and epistemological foundations can contribute to the foundations of the dialogues on Environment and Environmental Education. It is from this perspective that working with the environment in a privileged area of information and knowledge production, can bring holistic understanding, the exercise of citizenship and the problematization of the relationship "human-society-nature".
\end{abstract}

Key words: Environment, Higher Education, Environmental Education.

\section{Educação ambiental no ensino superior: diálogos reflexivos sobre meio ambiente}

\section{RESUMO}

O artigo apresenta uma reflexão sobre a possibilidade de dialogar sobre o Meio Ambiente no âmbito do Ensino Superior. Desse modo, em vista de ampliar a compreensão integral de suas dimensões (biológica, política, social e econômica), busca-se romper com sua restrita relação em preservar os seres vivos e a natureza, partindo para a construção de novas formas de articulação desta questão com a formação docente. Diante disso, optou-se pela pesquisa-ação, cuja metodologia fez uso da abordagem qualitativa, com dados coletados através da observação e pesquisa documental e bibliográfica. $\mathrm{O}$ objetivo geral pautou-se em analis ar quais fundamentos teóricos e epistemológicos podem contribuir para a fundamentação dos diálogos sobre o Meio Ambiente e Educação Ambiental. É nessa perspectiva que o trabalho com o meio ambiente em espaço privilegiado de informação e produção de conhecimento, poderá trazer a compreensão holística, o exercício da cidadania e a problematização da relação "ser humano-sociedade-natureza".

Palavras-chave: Meio Ambiente, Ensino Superior, Educação Ambiental.

\section{INTRODUÇÃO}

A intervenção humana sobre a natureza tem provocado destrutivos que colocam em perigo tanto os ecossistemas como o conjunto de toda a vida. A contaminação por dejetos tóxicos em mares e oceanos, a extinção de espécies animais e vegetais, bem como a miséria que se alastra por todo o planeta, demonstram a gravidade da crise ambiental que as sola o planeta. Segundo [1], na dinâmica das mudanças que ocorre na natureza com a intervenção humana, a Educação Ambiental deve ser articulada ao processo educativo, com a intenção de fomentar a construção de valores, que possibilitem ao ser humano rever a sua relação com os outros e com o mundo.

São metas da educação as mudanças de atitudes, desenvolvimento de habilidades e competências, bem como, a 
promoção de novos conhecimentos provenientes da percepção do ser humano como sujeito que tece no mundo e com o mundo suas descobertas criadoras. Contudo, não há dúvidas de que a educação sozinha não vai resolver todos os problemas do mundo.

O papel da Universidade nesse contexto pode ser de fundamental importância pois se remete a novas formas de encarar a relação entre ser humano e natureza, através de formas democráticas de atuação, baseadas em práticas interativas e dialógicas.

Mediante a recorrente presença de discussões acadêmicas no Brasil, na universidade, nos movimentos sociais ou na escola, os temas Meio Ambiente e Educação Ambiental não soam como novidade. Segundo [2], a abordagem a respeito dessas temáticas não passava de um ensino de ecologia atualizado.

De acordo com [3,4], no contexto brasileiro, após a década de 1970, iniciaram-se alguns debates abordando a questão ambiental, devido à influência dos movimentos internacionais, como a Conferência de Estocolmo, em 1972 [5] e a de Tibilisi, em 1977 [6].

\section{MATERIAIS E MÉTODOS}

Para a elaboração desse artigo utilizou-se o método de pesquisa bibliográfica, tendo principalmente como fonte de consulta artigos científicos, livros, anais de congressos e atualização via material disponível na internet. Diante disso, optou-se pela pesquisa-ação, cuja metodologia fez uso da abordagem qualitativa, com dados coletados através da observação e pesquisa documental e bibliográfica. Partes dos estudos exploratórios podem ser definidos como pesquisas bibliográficas, assim como certo número de pesquisas desenvolvidas a partir da técnica de análises e conteúdo.

\section{RESULTADOS}

Os principais eventos que marcam a caminhada da educação ambiental até os nossos dias têm demonstrado que, apesar do grande número de reuniões e documentos, ainda existe a necessidade de ampliar o currículo das escolas e universidades, com a preocupação de familiarizar o corpo discente com a complexidade dos problemas ambientais. Isto equivale a consideração de que a abrangência do termo ambiente ao estudo dos compartimentos bióticos e abióticos e as interferências sócio econômicas e culturais, precisam problematizar a participação do ser humano como elemento desgaste dos ecossistemas [16].

Diante do questionamento do fracionamento e compartimentalização do saber como determinação disciplinar, incapaz de explicar e resolver tal problemática, urge a necessidade de compreender a complexidade da problemática ambiental, bem como os múltiplos processos que a caracterizam. No entanto, "a re-totalização do saber" exigido pela problemática ambiental, não é a soma nem a integração dos conhecimentos disciplinares disponíveis [...]. Gestado através da transformação de um conjunto de paradigmas do conhecimento e formações ideológicas, o saber ambiental emerge a partir de uma problemática social que os questiona e os ultrapassa [17].

Os estudos sugerem uma dinâmica ativa envolvendo pesquisas a partir dos primeiros consensos mundiais em torno do tema de meio ambiente, cujo foco é a resolução de problemas na busca de mudanças comportamentais e ambientais.

\section{III.1 CONTEXTUALIZAÇÃO HISTÓRICA DA EDUCAÇÃO AMBIENTAL NO BRASIL E SUA PRÁXI NO AMBIENTE EDUCACIONAL}

Educação ambiental na modalidade formal é um tema relativamente novo, não apenas como política pública, mas como preocupação de educadores, crianças, jovens, pais e um crescente número de intelectuais e profissionais de variadas áreas.

Nos anos 60, nos países do Primeiro Mundo, a preocupação de sensibilização com o meio ambiente e com a natureza, como se falava na época se tornou um modismo, e passou a ser vinculada com a crítica mais profunda ao estilo de vida, valores e comportamentos de uma sociedade consumista e predadora.

Em [7] é destacado que o "ambiente", termo que passou a fazer parte da agenda mundial, nos anos 70, no bojo da crise econômica que se instalou na maioria das nações, apontava para a interferência da poluição e exaustão dos recursos naturais, no presente e no futuro da humanidade.

Em 1972, com a realização da Conferência das Nações Unidas sobre o Ambiente Humano em Estocolmo, o debate da então chamada "questão do meio ambiente" conquistou fórum político. Seguindo as recomendações dessa conferência foi criado o Programa das Nações Unidas para o Meio Ambiente (PNUMA), levado a efeito no ano seguinte.

Realizada em 1977, a Conferência de Tibilisi, no município de Geórgia (antiga União Soviética) consolidou as bases referenciais para a Educação Ambiental, estabelecendo princípios objetivos, estratégias e princípios adotados em todo o mundo. Ao tornar-se obrigatória nas escolas, a partir da implantação dos Parâmetros Curriculares Nacionais (PCNs), em 1997, a temática ambiental passou a integrar os componentes curriculares e temas transversais. Este documento apresenta o "processo dinâmico, integrativo, transformador, participativo dentre outros, esboçando um discurso adequado ao espírito da Conferência" [8].

Para [9], na atualidade, os termos "meio ambiente, cidadania e educação são palavras em proeminente exaustão". $\mathrm{O}$ meio ambiente, no Brasil encontra-se extremamente vulnerável e a Educação Superior, enfrenta sérios problemas de qualidade, distanciando-se dos patamares desejáveis de democratização. Pensar a formação dos educadores ambientais nos cursos de graduação das universidades, hoje, remete a ideia de interdisciplinaridade e totalidade dos campos pedagógicos, político, social e científico, assim como a articulação entre as "atividades de ensino, pesquisa e extensão, como princípio metodológico para estruturar e sistematizar essa formação" [10].

Além dessa preocupação de inserir os princípios problematizados da Educação Ambiental no currículo da educação superior, em instituições públicas e privadas, em 
conformidade com a lei $\mathrm{n}^{\circ}$ 9795/1999, há o entendimento da participação das universidades na formulação e execução de programas e atividades vinculadas à Educação Ambiental dentro e fora dos seus muros.

Em [11] o autor alerta para a urgência de uma "universidade ambientalmente responsável”, questiona a tímida inserção da Educação Ambiental nos cursos superiores e a lentidão com que essas instituições têm aderido a essa questão. Na resolução $n^{\circ}$ 2, de 15 de junho de 2012, publicada no Diário Oficial da União em 18 de junho de 2012, o Conselho Nacional de Educação estabeleceu as Diretrizes Curriculares Nacionais para a Educação Ambiental, em todos os níveis de ensino. No que tange a Educação Superior, sugere o aprofundamento do "pensamento reflexivo" mediante estudos científicos, socioeconômicos, políticos e históricos a partir da dimensão socioambiental, com ênfase na participação, cooperação, o senso de justiça e a responsabilidade da comunidade educacional em contraposição às relações de dominação e exploração presentes na realidade atual [12].

$\mathrm{Na}$ perspectiva de [13], as propostas que balizam esses projetos parecem "fragmentadas e reducionistas", pois, geralmente, restringem-se ao aspecto naturalista, com poucas discussões políticas, sociais e econômicas a respeito do tema meio ambiente, por isso, raramente dissertam sobre as relações entre ambiente e sociedade e a interdependência homemambiente.

Ao constatarem esse limite de entendimento, alguns estudiosos como [2,14,15], mencionaram a necessidade de inserção da Educação Ambiental crítica, por meio da qual criem-se condições para examinar o próprio cotidiano e propor alternativas coletivas e possibilidades de novos entendimentos sobre meio ambiente e sociedade.

A denominação Educação Ambiental surgiu a partir da Carta de Belgrado; registro documental elaborado por especialistas em educação, ecologia, dentre outras, sobre o qual estão assentados os "fundamentos básicos de uma proposta pedagógica que se convencionou chamar educação ambiental", e que se relaciona à cons cientização, capacidade de avaliação e participação dos educandos [16].

$\mathrm{Na}$ visão de [7], a história da Educação Ambiental, inicia-se no século XVIII, quando Rousseau (1712-1778), e mais tarde, o educador Freinet (1896-1966), no início do século $\mathrm{XX}$, insistiram na eficácia do meio como estratégia de aprendizagem. Contudo, educar para o meio foi um importante passo dessa nova abordagem educacional. Nos anos 60, a UNESCO (United Nations Educational, Scientific and Cultural Organization) em português Organização das Nações Unidas para a Educação, a Ciência e a Cultura, contabilizou 79 países que já incluíram essa educação no seu currículo escolar. A própria UNESCO recomendava a inserção dos aspectos sociais, culturais e econômicos no estudo biofísico do meio ambiente.

Devido sua ocorrência ter sido marcada por um contexto de crise ambiental, oriunda nas décadas finais do século XX, os princípios defendidos pela Educação Ambiental surgiram de forma romantizada, com forte tendência biologicista, despolitizada dos problemas ambientais e como demanda para que o ser humano adotasse uma visão de mundo e uma prática social capazes de minimizar os impactos ambientais então prevalecentes.
Repleta de avanços, recuos e contradições, a his tória da Educação Ambiental também abrange a complexidade de sua conceituação. Gomes [13] discorre sobre a existência de duas categorias:

(1) a conservacionista; bastante presente através de diversas entidades que defendem as matas, os animais, a natureza biofísica intocável. No outro extremo;

(2) a educação ambiental crítica; instigadora de diálogos acerca do meio ambiente, em suas dimensões biológica, social, cultural, política e econômica, não apenas a natural. Nessa perspectiva, as temáticas sobre produção e consumo, mobilidade, exclusão social, relações entre Estado e mercado, justiça social e ambiental, distribuição de renda e outros, são trazidas ao palco das discussões e problematizações.

Diante deste cenário, o papel das Universidades, relacionado à Educação Ambiental, não corresponde a uma tarefa simples, depreende-se a extrema necessidade de alguns enfoques curriculares guiados pelos princípios da sustentabilidade ecológica e da valorização da biodiversidade cultural, com enfoque na formação do pensamento reflexivo, "capaz de analisar as complexas relações da realidade social e natural sem perder a dimensão mais complexa do pensamento" [17].

Esboçada por [18], "a Educação Ambiental crítica consiste num espaço em disputa". Concomitante a isso, a Educação Ambiental deve ocorrer a partir do entendimento da realidade social vivida, com ação política de instrumentalização dos grupos sociais em situação de vulnerabilidade socioambiental e requer um posicionamento político claro para que se alcance o projeto político defendido.

Segundo [14], a Educação Ambiental "Crítica" é difundida no Brasil, como uma "concepção alternativa" [2] ou popular" [3], já que há uma abordagem que homogeneíza e superficializa o discurso da Educação Ambiental, a fim de enfraquecer o esclarecimento da responsabilização do indivíduo pelas modificações nos planos político, social, econômico e cultural.

A seguir teceremos algumas discussões envolvendo as políticas públicas e o Ensino Superior como disseminador da sustentabilidade.

\section{III.2 A EDUCAÇÃO AMBIENTAL RUMO AO DESENVOLVIMENTO SUSTENTÁVEL EM INSTITUIÇÕES DE ENSINO SUPERIOR}

Ao mencionarmos as ações e a construção da Política Pública de Educação Ambiental no Brasil, retomamos o ano de 1973, com a criação da Secretaria Especial do Meio Ambiente SEMA e a Divisão de Comunicação e Educação Ambiental, embrião do que viria a ser o Departamento de Educação Ambiental do Ministério do Meio Ambiente - MMA (DEA/MMA), um dos órgãos responsáveis pela implementação da política pública de Educação Ambiental, de acordo com [19].

No Brasil a Política Nacional de Educação Ambiental - PNEA foi promulgada pela Lei $N^{\circ}$ 9.795, de 27 de abril de 1999 e o Programa Nacional de Educação Ambiental ProNEA foi instituído pelo MMA. Além desses, como já foi exposto acima, existem também, os Parâmetros Curriculares 
Nacionais (PCN's), obra do MEC que trata a temática ambiental como conteúdo transversalde todas as disciplinas do currículo escolar [8].

$O$ resgate do significado da palavra política que significa limite em grego, talvez nos ajude a entender o verdadeiro significado da política, que é a arte de definir os limites, ou seja, o que é o bem comum [20].

Quando entendemos política a partir da origem do termo, como limite, não significa regulação sobre a sociedade, mas de uma regulação dialética sociedade-Estado que favoreça a pluralidade e a igualdade social e política. Assim, resgatar a política é fundamental para que se estabeleça uma ética da sustentabilidade resultante das lutas ambientalistas.

A educação ambiental surge como um processo educativo que conduz a um saber ambiental materializado nos valores éticos e nas regras políticas de convívio social e de mercado, que sugere a questão distributiva entre benefícios e prejuízos da apropriação e do uso da natureza. Portanto, a educação ambiental deve ser direcionada para a cidadania ativa considerando seu sentido de pertencimento e corresponsabilidade que, por meio da ação coletiva e organizada, busca a compreensão e a superação das causas estruturais e conjunturais dos problemas ambientais.

Analisando a ética da sustentabilidade e os pressupostos da cidadania, a política pública pode ser apreendida como um conjunto de procedimentos formais e informais que expressam a relação de poder e se destina à resolução pacífica de conflitos, assim como à construção e ao aprimoramento do bem comum. E nas instituições de Ensino Superior não é diferente, são iniciativas que não passam de momentos sem ecos maiores na sociedade que levem a uma mudança significativa de incentivo nessa área.

Segundo [21], o tema ambiental e a educação a ela relacionada nunca se degradaram tanto como nos dias atuais. Os investimentos e a centralidade dessas questões nas políticas empresariais, governamentais, não governamentais, familiares e individuais ficam na oratória e não há materialização dessa divulgada e imprescindível mudança cultural.

A Educação Ambiental recomendada na Política Nacional de Educação Ambiental [22] deve ser desenvolvida como uma prática educativa integrada, contínua e permanente em todos os níveis e modalidades do ensino formal. Então, o Ensino Superior não deve fugir à regra.

Mas como se fará isso no Ensino Superior? Sorrentino e Biosoli [21] trazem sugestões louváveis neste viés, as quais pontuaremos sucintamente a seguir:

O primeiro é o diálogo sobre utopias e valores. As instituições de Ensino Superior não podem descuidar dessa responsabilidade de propiciar, a cada um dos seus alunos, um questionamento profundo do consumismo que nos distancia de nós mesmos e de apresentar utopias de todos os tempos, motivando, em cada aluno, a construção de seus próprios valores e virtudes.

O segundo é a metodologia. A sugestão da Organização das Nações Unidas para a Educação, a Ciência e a Cultura (UNESCO) como ponto de partida, é interessante, pois enuncia quatro aprendizados essenciais ao futuro profissional do estudante-cidadão de todas as áreas e regiões: Aprender a aprender, Aprender a fazer, Aprender a estar junto e Aprender a ser.
O terceiro é um território prioritário para a atuação da Instituição, no qual ela fomente um coletivo educador formado por diversas outras instituições e pessoas que formulem e implantem cooperativamente um Projeto Político e Pedagógico estimulador de demandas para as suas atividades de Pesquisa, Ensino, Gestão e Extensão.

De acordo com [23], as universidades são espaços de conhecimento, pesquisa e ensino e, como consequência, de transformação da sociedade por meio do desenvolvimento intelectual e da liberdade de pensamento.

Diante disto, apoiamos [21], quando citam que a formulação e a implantação de políticas públicas comprometidas com a transformação de nossas sociedades em direção à sustentabilidade socioambiental exigem a ambientalização de todas as instituições e movimentos instituintes, e o papel a ser jogado pelas IES nesse panorama é absolutamente relevante.

A Universidade é um espaço privilegiado na questão da formação de indivíduos atuantes e conscientes criticamente das demandas da sociedade. Portanto, atendendo ao seu papel de responder tais demandas sociais, não pode deixar de contemplar estes elementos subjacentes à formação do profissional/cidadão. Isto é, um profissional que tem a capacidade de atuar em sua profissão sem deixar de elencar fatores de construção de cidadania e consciência como a EA, promovendo ainda uma aproximação entre o Ensino superior e o grande público.

\section{CONCLUSÕES}

Ao relembrarmos a história do início das discussões sobre a Educação Ambiental, foi possível verificar que os diálogos permearam em torno de tratar o meio ambiente como estratégias de ensino, principalmente para ensinar ciências. Logo mais adiante, de uma forma mais crítica na perspectiva, as temáticas são sobre produção e consumo, mobilidade, exclusão social, relações entre Estado e mercado. Estudando o meio ambiente e apropriação das áreas urbanas tornou-se um desafio, principalmente pela grande transformação que o meio ambiente passa. Os obstáculos enfrentados neste tipo de pesquisa referem - se à metodologia, ao método, aos conceitos que possam integrar as dinâmicas da sociedade e da natureza e como essas dinâmicas se materializam no espaço ambiental gerando princípios de sustentabilidade ecológica.

No resgate da concepção de educação como ato político, e com a visão de que a Educação Ambiental e a Sustentabilidade não podem ser dissociadas, a Universidade é de fato um espaço apropriado para iniciar a discussão crítica entre seus alunos. Porém, faz-se necessário fomentar este debate em todos os ambientes da sociedade, seja na escola, nas instituições públicas e privadas a fim de gerar políticas públicas de conscientização, juntamente com a participação da sociedade civil (diminuindo o distanciamento entre a academia e a sociedade). Desta forma, fomentar-se-á a inserção da temática ambiental nos currículos, um processo educativo eminentemente político, que visa ao desenvolvimento nos educandos de uma consciência crítica acerca das instituições, atores e fatores sociais geradores de riscos e respectivos conflitos socioambientais. Busca uma estratégia pedagógica do enfrentamento de tais conflitos a partir de meios coletivos 
trazendo o exercício da cidadania que trabalha na criação de demandas participativas, conforme requer a gestão ambiental. Tal ação permitirá a aquisição de uma bagagem cultural de clara orientação política e social, viabilizando-se como um instrumento de gestão, na medida que se volta para a construção de cidadania ativa, que reivindica para conquistar seus direitos e situa a importância da Educação Ambiental em meio às forças e dinâmicas conflituosas que habitam o meio social.

A Educação Ambiental apoiada em uma teoria crítica que exponha com vigor as contradições que estão na raiz do modo de produção capitalista, deve incentivar a participação social na forma de uma ação política. Como tal, ela deve ser aberta ao diálogo e ao embate, visando à explicitação das contradições e observando os projetos societários que estão nesta disputa.

A formação epistêmica de educadores/as em todos os níveis e campos do saber precisa inserir em seu cotidiano, a análise crítica, a produção de conhecimento acerca da crise socioambiental contemporânea e ações para transformação dessa realidade. Engajar o tema no espaço da academia é condição necessária para o primeiro passo da tomada de discussão com a sociedade civil, seja através de atividades de extensão ou produção propriamente dita.

As discussões não devem se limitar apenas às teorias e às mudanças de padrões de vida voltados apenas na base no setor produtivo para garantir um ambiente saudável e equilibrado para a humanidade. Mas trazer a clareza de como é possível agregar a participação das pessoas nessas ações de mudança ambientais, bem como inserir de fato estas práticas e ensinos no ambiente escolar, seja com suportes informativos, materiais didáticos aliados à práticas docentes, a fim de desenvolver Habilidades e Competências que preparem uma geração futura que seja consciente de sua parcela de participação e responsabilidade de atuação social na questão.

Dessa forma, a pesquis a realizada vis ou analis ar quais fundamentos teóricos e epistemológicos podem contribuir para a fundamentação dos diálogos sobre o Meio Ambiente e Educação Ambiental no Ensino Superior.

\section{V.REFERÊNCIAS}

[1] Mamede, F.; Fraissat, G. Construindo Com Arte o Nosso Meio Ambiente. In: Santos,J.; Sato, M. A Contribuição Da Educação Ambiental À Esperança De Pandora.

São Carlos, Rima, 2001.P. 497-507.

[2] Layrargues, P.P.; Lima, G.F.C. Mapeando as macrotendências político pedagógicas da educação ambiental contemporânea no Brasil. In: VI Encontro Pesquisa em Educação Ambiental, 2011, Ribeirão Preto. VI Encontro de Pesquisa em Educação Ambiental: a pesquisa em educação ambiental .

[3] Carvalho, I. C. M. Educação Ambiental: a formação do sujeito ecológico. São Paulo: Cortez, 2008.

[4] CONFERÊNCIA MUNDIAL DE MEIO AMBIENTE E DESENVOLVIMENTO ONU, 1972, Estocolmo. Declaração de Estocolmo. Estocolmo: ONU, 1973.
[5] CONFERÊNCIA INTERGOVERNAMENTAL DE EDUCAÇÃO AMBIENTAL UNESCO, 1997, Tbilisi. Declaração de Tbilisi. Tbilisi: UNESCO, 1978.

[6] REIGOTA, M. O que é educação ambiental. São Paulo: Brasiliense, 2006.

[7] Leonardi, M. L. A. A Educação Ambiental como um dos instrumentos de superação da instabilidade atual. In Cavalcante. Meio Ambiente, Desenvolvimento e Políticas Públicas. 20ª Ed. São Paulo: Cortez, 2002.p. 391-408.

[8] BRASIL. Secretaria de Educação Fundamental. Parâmetros Curriculares Nacionais dos anos finais: meio ambiente e saúde. Brasília, MEC, 1998.

[9] Soffati, A. Fundamentos Filosóficos e Históricos para o exercício da cidadania e da educação. In: LOUREIRO, F.B., et al.(Orgs.)Educação Ambiental: repensando o espaço da cidadania. São Paulo: Cortez, 2002.p.23-67.

[10] Tozzoni-Reis, M. F. C. Educação Ambiental: referências teóricas no ensino superior .Comunic, Saúde, Educ, v.5, n.9, p.33-50,

2001.

Diponível:<http://www.scielosp.org/pdf/icse/v5n9/03.pdf >.Ace sso:05 de out. de 2016.

[11] Silva, A. D. V. Sustentabilidade no ensino superior: a emergência de uma universidade ambientalmente responsável. In: Guerra, A. F. S. \& Taglieber, J. E. (Orgs.). Educação Ambiental: fundamentos, práticas e desafios. Itajaí: Universidade do Vale do Itajaí, 2007. p.143-162.

[12] BRASIL. Lei 9.795, de 27 de abril de 1999 - Política Nacional de Educação Ambiental. Brasília, 2012.

[13] Gomes, S. R. A escola, seu entorno e os espaços nãoformais: possibilidades de diálogos sobre meio ambiente. Dissertação apresentada ao Programa de Pós-Graduação em Educação e Ensino de Ciências na Amazônia, da Universidade do Estado do Amazonas - UEA, 2015.

[14] Guimarães, Mauro. A formação de educadores ambientais. Campinas, SP: Papirus, 2004.

LIMA, Gustavo. Crise ambiental, educação e cidadania. In: Layrargues, Philippe (org.). Educação Ambiental: repensando o espaço da cidadania. São Paulo: Cortez Editora, 2002.

[15] Loureiro, F.B., et al. (Orgs.). Educação Ambiental: repens ando o espaço da cidadania. São Paulo: Cortez, 2002.

[16] Depresbiteris, L. Avaliação da aprendizagem na Educação Ambiental: uma relação muito delicada. In: Santos, J.; Sato, M. A contribuição da Educação Ambiental à esperança de Pandora. São Carlos, Rima, 2002.

[17] Leff, Enrique. Saber Ambiental: sustentabilidade, racionalidade, complexidade, poder. Petrópolis, RJ: Vozes, 2007. 
[18] Santana, L. C. Pesquisa em educação ambiental e

políticas públicas: apontamentos e memória de um processo.

Pesquisa em Educação Ambiental, vol. 9, n. 1. 2014. p. 156-

168. 